\section{Halley's comet} \section{Europe's hopes for second probe}

GiotTo, the European Space Agency's first interplanetary satellite, designed to intercept Halley's comet, should be backed up by a second version which could be built at relatively little extra cost, some Europeans claim. Spare parts and a spare framework are already available, and could be assembled to make a Giotto II.

British Aerospace, prime contractors for Giotto, was not prepared last week to quote a price for such a project but, according to some estimates, a second Giotto, including launch, would cost only half as much as the current mission: another $£ 50$ million on top of the present $£ 100$ million.

The advantages of a second Giotto would be as a safeguard against the failure of the Ariane launcher, two of whose last six launches have failed. But if that launch were successful, a second Giotto could provide a matching experiment to send to another comet. The other missions to Halley, the Soviet Union's Vega craft and Japan's Planet-A and MST-5, are already double missions.

"This is a hot potato in ESA (European Space Agency) at the moment", said a Giotto specialist last week. It would put the f80-million-a-year ESA scientific programme back only a few months, he claimed, saying that it is "up to the scientific community" to decide whether it wanted to do it.

One planetologist in favour of a second spacecraft is Tony McDonnell of the University of Canterbury. He has already proposed a mission called Comex, which would be a modified Giotto II designed to intercept a number of comets by using direct orbital injection from Ariane and by carrying a liquid fuel motor aboard. Comets differ greatly from one another, McDonnell points out, some bursting, others splitting with a variety of tails and emission characteristics, and there is a danger that the Halley data will give too selective a view of cometary structure and chemistry.

ESA planners, however, take the view that any modification of the tightlydesigned Giotto mission would entail its total redesign and thus destroy the advantages of using Giotto spare parts. Giotto uses a solid fuel booster which can only be fired once to reach its interception orbit

with Halley, and so a Giotto II could be used effectively only for another single comet.

There may, however, be other arguments for a Giotto II. Giotto will go far closer to the comet nucleus than any other mission. (The closest approach will be less than $1,000 \mathrm{~km}$, compared with upwards of $10,000 \mathrm{~km}$ for the Soviet and Japanese probes and for the American ISEE satellite recently diverted to comet Jacobini-Zimmer.) So, says Giotto's project scientist Ruediger Reinhard, Giotto has only a small chance of surviving the encounter.

Moreover, it is now clearly admitted, impacts with cometary dust in at least the last "tens of seconds" of the 30-minute passage of Giotto through the cometary coma to the nucleus are likely to throw out the close $\left(1^{\circ}\right)$ alignment of telemetry with the Earth, so that the last portion of data is in danger of being lost. And this assumes the dust cloud to be uniform; if Giotto were unfortunate enough to meet a jet of emission (such as are observed), misalignment would occur earlier.

There will be attempts to steer Giotto between any jets observed from Earth by taking the best straight-line path. But it is agreed that the whole exercise is risky. "We will know the risk sometime between 1830 hrs on 13 March 1986 and 0330 hrs on the next day", when the encounter takes place, said a British Aerospace spokesman.

- A rumour is circulating at the British Aerospace Dynamics Group near Bristol, where Giotto is being assembled, that Mrs Margaret Thatcher the British Prime Minister has enquired of an official whether Halley would be destroyed if Giotto targetting were so good that the satellite hit the nucleus (which is believed to be about $3 \mathrm{~km}$ in radius). The political consequences of such a conflagration would clearly be incalculable. But whether or not the question was actually put, British Aerospace did tackle the calculation. Little damage would be done, it seems, even though the impact would take place at 68 $\mathrm{km}$ per second. This velocity gives Giotto kinetic energy equivalent to about 250 kilotons of TNT, but the latent heat of melting of the cometary snowball would be some 100 million times greater.

Robert Walgate

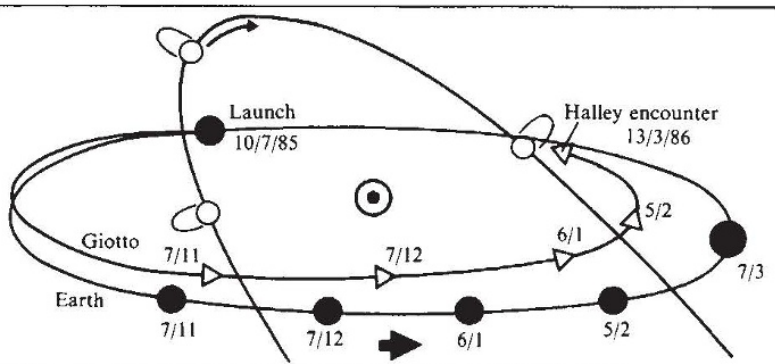

The orbits of Halley, Earth and Giotto, assuming a launch on $10 \mathrm{July} 1985$
European pollution West Germany takes the lead

WEST Germany is well on its way to leading the European Economic Community (EEC) in environmental legislation. The impetus is the growing anxiety about the condition of West German forests (see figure opposite, and Nature 307,97 ; 1983). A government committee, Der Rat von Sachverständigen für Umweltfragen, has now stressed that the phenomenon "can no longer be explained on the basis of traditional forest experience", but that acid air pollution must be an important contributory cause. But there are now also fears that air pollution is increasing mortality among the vulnerable trees - the old and the very young. Mortality among the young may be especially severe in West Germany, which now has the lowest success rate for new trees in the world.

The response to the anxiety has been impressive. In a debate in the Bundestag, the Federal Minister of the Interior, Dr Friedrich Zimmermann outlined a series of measures being taken in West Germany. The federal government is spending DM56 million ( $£ 14$ million) a year on research related to forest death (compared with an estimated $£ 0.5$ million in the United Kingdom. Individual Länder are also reacting - Baden-Württemberg, which sent a delegation to Japan to investigate power-plant desulphurizing techniques, now has three pilot plants built at a total cost of DM 60 million ( $£ 15$ million) without federal or EEC support.

West Germany emits 3.5 million tonnes of sulphur dioxide a year into the atmosphere, 43 per cent of it from power stations. Regulations introduced last year set the emission levels for new power plants at $1,800 \mathrm{mg} \mathrm{m}^{-3}$ and twice that for old plant. The utilities claim the new regulations will cost them DM10,000-15,000 million ( $£ 2,500-3,740$ million); $20-30$ per cent of the cost of new plant is already attributed to measures designed to protect the environment.

The West German environment council is nevertheless pressing for the emission levels to be further reduced, perhaps closer to the Japanese limit of $100-500 \mathrm{mg} \mathrm{m}^{-3}$. Even so, new regulations would reduce total annual emission of sulphur dioxide to 0.55 million tonnes a year within 10 years. (The opening by Rheinischen Braunkohlenwerke AG of what will be the largest brown coal mine in the world, with reserves of 2,500 million tonnes to be exploited over the next 50 years, may make that harder to achieve.)

Nitrogen oxides from vehicle exhausts are another target for current concern. One controversial estimate is that the introduction of a speed limit, of 80 kilometres per hour in general and 100 kilometres per hour for autobahns, would reduce emis- 